\title{
The Influence of Authority Leadership on Employee Innovation Behavior: A Mediator Model of Double Adjustment
}

\author{
Zheyuan Zhang ${ }^{\mathrm{a}}$, Lu Ma ${ }^{\mathrm{b}}$ \\ Guangxi University of Science and Technology, Liuzhou 545006, China. \\ a425967642@qq.com, bmalu6655@163.com
}

\begin{abstract}
Keywords: Authoritarian Leadership, Leadership-Member Exchange, Leadership Approval, Innovation Self-Efficacy, Employee Innovation Behavior.
\end{abstract}

\begin{abstract}
Based on the viewpoints of social cognition and social exchange and cognitive theory, this paper studies the influence of authoritarian leadership on employee innovation behavior based on the practice of enterprise management, and establishes an intermediary model with two-stage adjustment, that is, the exchange of leaders and members and the innovation of self-Effectiveness at Different Stages Adjusting Authoritarian Leadership Through the role model of leadership identity that influences employee innovative behavior, we explore internal mechanisms and boundary conditions that might lead authoritarian leaders to exert their positive effects. This article provides a brand-new research idea for China's unique authoritarian leadership style, presents a unique framework and concept for the management theory in the context of our organization, and provides a completely new understanding of the authoritarian leadership and its impact on employees Inspiration, the relevant business management practices provide some useful reference.
\end{abstract}

\section{Introduction}

At present, our country has entered a critical period of transformation and development and various management situations are emerging one after another. However, under the influence of the deeply rooted Chinese traditional culture, the authoritarian leadership style still has profound cultural accumulation in the organizational context of our country. In recent years, with the increase of scholars' attention to the "dark" or negative leadership behavior, authoritarian leadership has been studied and discussed by most scholars as typical representatives of disruptive leadership styles. That is, studies have shown that authoritarian leaders will have a certain degree of negative impact on employee psychology, emotion, attitude and behavior. However, some studies argue that the relationship between authoritarian leadership and employee performance or organizational attitudes is weak and in some cases even has a positive impact. On the day-to-day management practices of enterprises, such as Steve Jobs and Apple's innovation, Dong Mingzhu and Gree's reform, Ren Zhengfei led Huawei to the world, etc., authoritarian leadership behavior also seems to be able to give enterprises a certain degree of positive effect. Therefore, based on the different conclusions of previous studies and the actual situation of the organization, the contradiction between theory and practice prompts us to further study and determine the relationship between authoritarian leadership and employee outcomes and explore the contextual factors that may strengthen or weaken the relationship.

\section{Authoritarian leadership, leadership recognition and employee innovation}

With the development of the Internet, the era of big data and artificial intelligence has been opened up and more and more science and technology-based enterprises are born. "Innovation" as an inexhaustible motive force for the development of enterprises, especially science and technology-based enterprises, has drawn great attention. Employee innovation is the basis of enterprise innovation. How to enhance employee awareness of innovation and motivate employees to innovate have become the major issues that enterprises have to solve problem. In addition, in the 
ever-changing market environment, competition, transformation, transformation and upgrading all make enterprises under tremendous pressure. The risks of innovation and the uncertainties of the future for employees lead the enterprises to need a strong and trustworthy leader. To some extent, authoritarian leaders can be a good choice.

Relevant studies have found that the authoritarian leadership is different from other negative leadership styles. The most fundamental reason why authoritarianism, control and education are the behaviors is that they have the leadership they have been given. This is a hidden, very far-sighted and objective ability to actively do things, is a powerful motivation that may be recognized and recognized by employees, which translates into employee confidence, responsibility and security. Therefore, this study argues that as a unique style of leadership in a science and technology-based enterprise, authoritarian leadership may be recognized by its subordinates under certain circumstances and positively affect subordinates' attitudes and behaviors. Staff approval of authoritarian leadership, in addition to the field of production safety, seldom by scholars attention. In view of this, this study argues that leadership identity can be used as an intermediary variable to explore the inherent mechanism of authoritarian leadership on employee innovation behavior.

\section{Leadership - members of the exchange relationship between the regulatory role}

In our organizational context, "relationship" as a special kind of affective orientation has an important influence on employees' cognition and behavior. Leadership-member exchange has an important role in establishing trust and security among leaders and employees, and in maintaining mutually beneficial relationships. In addition, employees 'assessment of their relationship with the leadership is also one of the important factors in their formation of leaders' approval. High Leadership - The quality of member exchange helps to increase the interaction between leaders and members and enables superiors and subordinates to jointly create an organizational context based on emotion and trust. First, the higher the quality of the relationship between leaders and employees, the greater the staff's ability to gain more insight and understanding of leadership, such as beliefs, missions, and values, and more likely to create a sense of trust and trust with leaders. Their leadership traits, behaviors and goals are mapped to their own values and direction to better define themselves as members of the leadership. Second, with the improvement of the quality of exchange relations with leaders, authoritarian leaders will also change their attitude and behavior to a certain extent. For "insiders" will show their father's "strict love" and give employees more More formal and informal support or authorization so as to effectively enhance employees "'insider awareness" so that employees can better understand leaders' behavior and style of presence, demonstrate unconditional compliance with authoritarian control, and show their modesty for harsh teachings And acceptance, recognition and leadership of the leadership of its absolute loyalty and trust, and encourage staff to feel more leaders care, guidance and help and strong leadership, which is conducive to its realization of self-worth, to find and The leader of a unified understanding.

In a word, high-level leaders - members who exchange quality will increase their emotional attachment to the leader, have strong trust in the leader, confidence in work and sense of psychological security, agree with the leader of the authoritarianism, and be guided by values and behaviors, Working style and other aspects of the same with the leader, willing to obey the instructions of the authoritarian leader, under the control of the authoritarian leaders can collaborate with the organization's goals and vision. High Leadership - The quality of member exchange helps employees re-define themselves in the organization and enhance their self-esteem to increase leadership recognition. Therefore, this study argues that employees with a higher leadership-member exchange relationship are more likely to gain approval for authoritarian leaders and thus have a positive behavioral performance, that is, the leadership-member exchange relationship may be between authoritarian leadership and leadership recognition Between the mediation play a positive role. 


\section{Innovation self-efficacy of the regulatory role}

As before, it is assumed that employees in a tech-savvy firm agree that authoritarian leadership may trigger innovation, but this connection may be stronger if employees consider themselves innovative employees. Innovative ideas and products are often challenged or challenged by tech startups before they occur, requiring that creative individuals have the confidence and the positive attitude to face them in the face of frustration and resistance. From the social cognitive theory, we can see that the key variable that motivates human behavior and motivation is self-efficacy, so scholars gradually begin to explore the impact of innovative behavior.

With the deepening of research, the role of employee creativity self-efficacy in employee innovation has become increasingly prominent. The researchers found that there is not only a significant positive correlation between employee creativity self-efficacy and employee innovation, but also a small amount of research shows that employees Creativity Self-efficacy can play a regulatory role in the process of employee innovation behavior formation. In general, innovation self-efficacy is the "driving force" for employee innovation. For employees, innovation requires a strong internal motivation in addition to a supportive work environment, a high level of innovative self-efficacy that inspires innovative ideas and overcomes the challenges and challenges of putting ideas to life. Therefore, we believe that the process of authoritarian leadership influencing employee leadership identity and hence employee innovation behavior is likely to be moderated by innovation self-efficacy. Therefore, this study suggests that having a higher level of creative confidence and belief can effectively enhance the relationship between leadership identity and employee innovation behavior, that is, innovation self-efficacy can play an active mediating role in leadership identity and employee innovation behavior.

\section{Summary}

In general, in order to solve the problem that the authoritative leadership of traditional theory only has a negative impact, this study, based on the perspective of social cognition, combined with social exchange and cognitive theory, established a multi-stage regulation based on the practice of enterprise management The intermediary model. Specifically, this study argues that employees' recognition of leadership can effectively affect the relationship between authoritarian leadership and employee innovation behavior, and the process of this relationship also depends on the quality of the exchange relationship between employees and leaders and the individual's own The level of conviction that results in innovation. This article provides a brand-new research idea for China's unique authoritarian leadership style, provides empirical support for better exerting the superiority of authoritarian leadership, and proposes a unique framework and conception for the management theory under the organizational context of our country. It is worth emphasizing that this study has unique significance in the Chinese context and provides a completely new inspiration for a comprehensive understanding of the influence of authoritarian leaders and their employees. It also provides some useful references for the management practices of related enterprises. The research framework is shown in Figure 1.

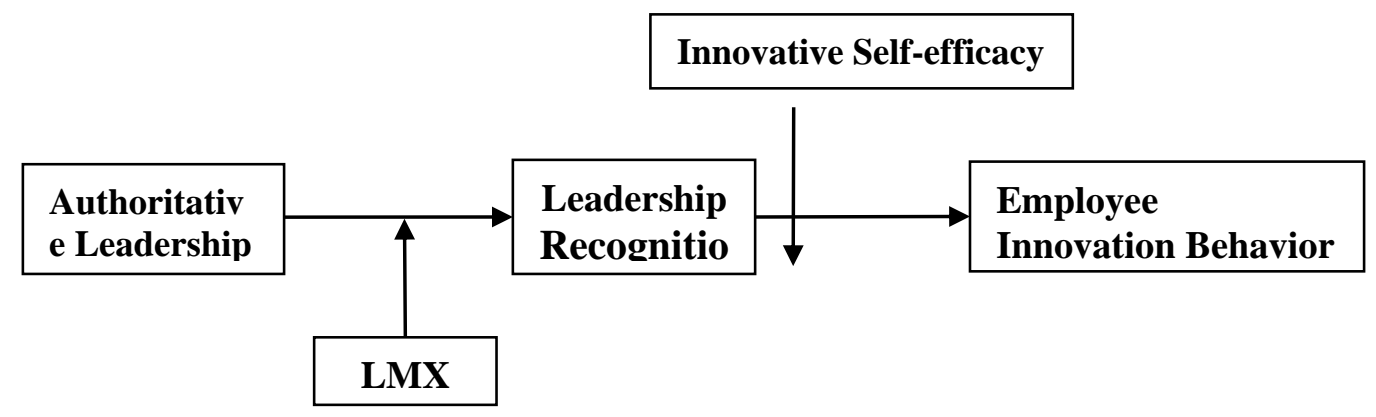

Figure 1 Research model 


\section{Acknowledgements}

Guangxi University of Science and Technology Graduate Innovative Project, NO: GKYC201611, GKYC201612, GKYC201613.

\section{References}

[1] Chou, W. J., Chou, L. F., Cheng, B. S., \& Jen, C. K. Juan-chiuan and shang-yan: The components of authoritarian leadership. Indigenous Psychological Research in Chinese Societies,2010, 34, 223-284.

[2] Chen X P, Eberly M B, Chiang T J, et al. Affective trust in Chinese leaders: : linking paternalistic leadership to employee performance[J]. Journal of Management, 2011, in press(in press):796-819.

[3] Zhang Y, Chen C C. Developmental leadership and organizational citizenship behavior: Mediating effects of self-determination, supervisor identification, and organizational identification[J]. Leadership Quarterly, 2013, 24(4):534-543.

[4] Walumbwa F O, Hartnell C A. Understanding transformational leadership-employee performance links: The role of relational identification and self-efficacy[J]. Journal of Occupational \& Organizational Psychology, 2011, 84(1):153-172.

[5] Yang K, Yan X, Fan J, et al. Leader-follower congruence in proactive personality and work engagement: A polynomial regression analysis[J]. Personality \& Individual Differences, 2017, 105:43-46.

[6] Wang X H, Howell J M. A multilevel study of transformational leadership, identification, and follower outcomes[J]. Leadership Quarterly, 2012, 23(5):775-790. 